\title{
A dimensão figurativa em poemas de A educação pela pedra, de João Cabral de Melo Neto
}

Fabiane Renata BORSATO

(Centro Universitário Barão de Mauá,

Ribeirão Preto)

RESUMO: Análise da recriação sintática dos versos de "A urbanização do regaço" e "O regaço urbanizado", de João Cabral de Melo Neto, da obra A educação pela pedra, para compreensão dos jogos figurativos da linguagem que se ligam à isotopia temática da sexualidade e sedução desencadeada pela arquitetura sevilhana.

PALAVRAS-CHAVE: poesia; João Cabral; A educação pela pedra; espacialidade; isotopia

ABSTRACT: Analysis of the syntactic recreation of "A urbanização do regaço" and "O regaço urbanizado", by João Cabral de Melo Neto, in his work A educação pela pedra, for the understanding of the figurative language games connected to the thematic isotopy of sexuality and seduction triggered by the sevillian architecture.

KEYWORDS: poetry; João Cabral; A educação pela pedra; spatiality; isotopy 


\section{INTRODUÇão}

A obra A educação pela pedra (1962-1965) apresenta 48 poemas, divididos em quatro partes, cada qual contendo doze poemas, intituladas Nordeste (a), Não Nordeste (b), Nordeste (A), Não Nordeste (B). Há forte relação de contigüidade entre os textos, expressa pela permuta de versos e pela marca dissertativa proveniente da discussão de imagens, traço qualificado pelo crítico Ángel Crespo como "cierto barroquismo, más propenso a lo conceptista que a lo culterano" (Crespo, 1990:26).

Os textos "A urbanização do regaço" e "O regaço urbanizado" pertencem à sessão Não Nordeste (B). Esta parte recebe tratamento estrófico idêntico ao da parte A, poemas de 2 estrofes de 12 versos cada ("A urbanização do regaço") ou poemas de 2 estrofes, sendo a primeira de 16 versos e a segunda de 8 ("O regaço urbanizado").

A arquitetura da obra A educação pela pedra apresenta rigoroso planejamento, em que um poema desdobra-se em outro ou revela as contradições do outro, em relações de contrariedade ("O mar e o canavial", "O canavial e o mar"), complementaridade ("Coisas de cabeceira, Recife", "Coisas de cabeceira, Sevilha"), implicação ("A urbanização do regaço" e "O regaço urbanizado").

No poema 1, "A urbanização do regaço" (anexo 1), o sujeito bairros mais antigos de Sevilha está em processo de realização da urbanização do regaço e deve, ao concluí-la, sensibilizar timicamente o gosto pelo regaço sevilhano e sua percepção como objeto de valor desejável pelo destinatário. Os bairros mais antigos de Sevilha são flagrados em processo de reorganização figurativa da topografia (urbanização ${ }^{1}$ ) para que atores tímidos e introspectivos, ameaçados pelo olhar do outro, encontrem a continuidade do íntimo no exposto.

O poema 2, intitulado "O regaço urbanizado" (anexo 2), apresenta o particípio passado, verbo de aspectualidade conclusiva, revelador da finalização do processo de urbanização desenvolvido no texto 1 . Este segundo texto propõe nova performance de atração de sujeitos para os bairros antigos de Sevilla, criando o gosto pelo espaço urbanizado.

\section{2. “A URBANIZAÇÃo DO REGaÇO” E "O REGAÇO URBANIZADO": IMPLICAÇÃ̃O E COMPLEMENTARIDADE}

No texto "A urbanização do regaço", os versos apontam o processo de urbanização do regaço sevilhano, a qualificação do destinatário e do espaço urbanizado e os procedimentos de atuação no novo espaço:

- Os dois primeiros versos enunciam o ato de criação da urbanização.

- Os quatro seguintes explicam o porquê da urbanização e a quem ela é destinada, questões reforçadas nos versos 21 a 24.

- Os versos 7 a 10 e 13 a 16 descrevem a maneira como é feita a urbanização.

- Os versos 11 e 12, 19 e 20 enumeram os benefícios da criação.

- Enquanto os versos 17 e 18 colocam-nos frente à necessidade de criar o gosto pela urbanização, ação em processo de realização. 
A permuta de versos e palavras no poema 2, "O regaço urbanizado", leva à alternância e à imagem de situação contígua entre objeto de valor e destinatário. A relação de complementaridade advém da justaposição em repetição dos dois versos anteriores:

Com ruas feitas apenas com esquinas e por onde o caminhar fia quadrado, para quem sente nu no meio da sala e se veste com os cantos retirados.

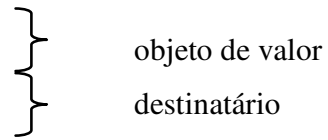

com ruas medindo corredores de casas, onde um balcão toca o do outro lado, para quem torce a avenida devassada e enfia o embainhamento de um atalho,

$\left\{\begin{array}{l}\text { objeto de valor } \\ \text { destinatário }\end{array}\right.$

"O regaço urbanizado" compõe-se dos mesmos versos de "A urbanização do regaço", organizados em ordem distinta. O título sugere relação continente-conteúdo, já que o regaço assume o estado de urbanizado graças à ação de urbanização expressa no primeiro poema. Conforme Secchin: os títulos de ambos já estão, virtualmente, "um no outro", os textos, em sua íntegra, "têm o aconchego que a um corpo/ dá estar noutro, interno ou aninhado"(Secchin, 1985:247).

O sujeito manipulado movimenta-se rumo ao objeto regaço, movimento que a fenomenologia chama de intencionalidade, e que no poema apresenta-se como uma direção vetorial em que os signos são tensionados para a instauração de semas da sedução, da privacidade e do aconchego, inerentes aos bairros mais antigos de Sevilha e que lhe dão competência modal para o fazer "urbanização do regaço". O objeto é concebido como fenômeno apreendido pelo apelo sensorial e perceptivo, portanto conhecer suas múltiplas feições é entender o contributo que o espaço pode oferecer ao conhecedor.

Os poemas apresentam em sua estrutura sintática dois actantes principais figurativizados pelos bairros mais antigos de Sevilha (actante 1: manipuladordestinador-destinatário) e pelo destinatário (actante 2).

O actante 1 é identificado; enquanto o outro beneficiário do processo é descrito por meio do pronome eles, o que demonstra indivíduos que mantêm sua identidade em sigilo e estendem a busca da privacidade aos regaços urbanizados. Essa coerência sustenta-se nos versos 3 e 4 do poema 1 - "para quem, em meio a qualquer praça,/ sente o olho de alguém a espioná-lo". A expressão em meio a qualquer praça, entreposta nos versos mencionados, teria sua ordem direta depois do verbo espioná-lo, como locução adverbial de lugar. Esse recurso atinge tanto o significante, expresso pela interposição dos termos; quanto o significado, indicativo do grau de invasão que esses olhos exercem sobre os transeuntes, olhos que se localizam em pontos estratégicos da praça, capazes de ver tudo, de ver "entre" e "em meio a". Tal procedimento também ocorre nos versos 23 e 24 . A interposição da expressão quando fora de casa denota a situação específica do querer do sujeito fora de seu ambiente íntimo. Ele quer "dentros e resguardos de quarto" quando deslocado - qual está o significante - de seu espaço. 
O actante 1 possui como competência modal a criação e como resultado performático a urbanização do regaço e o gosto pelo regaço urbanizado, sintaticamente objetos diretos.

Ao actante 1 cabem as orações principais quando destinador-manipulador:

1. Os bairros mais antigos de Sevilha

2. criaram uma urbanização do regaço,

E quando destinatário: orações passiva, subordinada adverbial consecutiva ou adjetiva reduzida de gerúndio:

3. Com ruas feitas com pedaços de rua,

4. se agregando mal, por mal colados,

5. Com ruas medindo corredores de casas,

Ao actante 2 são destinadas orações subordinadas adverbiais finais e consecutivas:

6. para quem, em meio a qualquer praça,

7. sente o olho de alguém a espioná-lo,

8. para quem sente nu no meio da sala

9. e se veste com os cantos retirados.

A ação reflexiva de urbanizar-se propicia ao actante 1 a aquisição de abrigos e íntimos de corpo, destinados à persuasão do actante 2 , tentado pelo objeto de valor eufórico e atraente - o aconchego do regaço. O actante 1 cria a nova topografia e o gosto por ela; atraindo o actante 2 que se apresenta modalizado por um querer "dentros e resguardos de quarto quando fora de casa".

O processo de auto-urbanização do regaço oferece a ilusão de eliminação da exposição característica do espaço exterior àqueles que buscam intimidade.

O título carrega a distância semântica existente entre urbanização e regaço. $\mathrm{O}$ primeiro refere-se ao ato de urbanizar e dotar a cidade de infra-estrutura para o processo de concentração populacional, trata-se do planejamento espacial ordenado com vistas à concepção de local público e freqüentável. "Regaço" remete ao universo privado, ao espaço compreendido entre cintura e joelhos, local do aconchego. A heterogeneidade figurativa proporciona distantes e imprevisíveis correspondências analógicas, paradoxo que se resolve na imagem da Sevilha feminina, receptiva, acolhedora. Seus espaços sinuosos, suas ruas estreitas compõem ninhos de acolhimento daqueles que a percorrem (anexo 3).

O sujeito ativo "bairros mais antigos de Sevilha" empreende a ação topológica de urbanizar seus regaços e espaços íntimos, cujo destinatário é o sujeito passivo ávido de intimidade. O regaço sevilhano comporta o sema do acolhimento uterino - abrigos, desvãos, aconchego, estar noutro aninhado e do coito - íntimos de corpo, esconsados, estar noutro interno, enfia o embainhamento, dentros e resguardos de quarto.

O núcleo sêmico do poema apresenta o classema da espacialidade e os traços /exterioridade/ e /interioridade/. Deslocar-se pela topografia sevilhana significa 
desenvolver trajeto que vai da mobilidade e do deslocamento por espaços abertos e devassados à imobilidade e à interiorização do regaço. As figuras a seguir, extraídas do texto poético, revelam o trajeto:

- bairros - praça - meio da sala - cantos retirados

- ruas - pedaços de rua - esquinas - abrigos - recantos em desvão e esconsados

- ruas - corredores de casas - balcão

- ruas - becos

- $\quad$ avenida devassada - atalho - dentros e resguardos de quarto

O espaço sugestivo de amplitude vai gradativamente dando lugar ao espaço íntimo, num movimento de interiorização que gera os semas da sexualidade e da feminilidade, traços inerentes ao espaço sevilhano e à região de Andaluzia, como é possível observar em outros poemas de Cabral, como "Nas covas de Baza", "Nas covas de Guadix", de A educação pela pedra. Os poemas referidos apresentam o feminino ora como local da sexualização; ora como espaço maternal e uterino, de anulação da sexualização, o "dormir de feto, não o dormir de falo" (Nas covas de Guadix).

A terra feminina é lugar da possibilidade de relação uterina e/ou fálica. A interação entre os semas da masculinidade e da feminilidade sugere o ato sexual, expresso especialmente nos versos finais:

e enfia o embainhamento de um atalho, para quem quer, quando fora de casa, seus dentros e resguardos de quarto.

A nova topografia é espaço tensivo capaz de propor a relação juntiva dos universos interoceptivo e exteroceptivo. O sujeito 1, bairros mais antigos de Sevilla, atua para a percepção da extensidade de sua topografia por parte do sujeito 2, destinatário, que está na ordem do sentir. O processo de urbanização parte da extensidade, traço dos locais públicos e externos, em direção ao espaço íntimo, interno. A percepção dos olhos observadores e desautorizados de outrem conduz o destinatário à busca de privacidade que se dá na ordem do sentir. O verbo sentir aparece duas vezes, relacionado à sensação de ser espionado, de estar nu, desprotegido:

para quem, em meio a qualquer praça,

sente o olho de alguém a espioná-lo,

para quem sente nu no meio da sala.

O sentir modaliza o sujeito para o ato de vestir-se, semantizando a busca de privacidade, ação que assume a direção vetorial de fora para dentro: $e$ se veste com os cantos retirados.

O terceiro verbo assumido pelo destinatário é torcer: para quem torce a avenida devassada, verbo que tem, dentre outros significados, o de dar a volta sobre si mesmo, ação que pode semantizar recolhimento.

Os bairros mais antigos de Sevilha atraem, com sua estrutura simultaneamente privada e pública, o destinatário - sujeito 2 . No poema 2 , o título anuncia a realização 
da ação pela derivação sufixal -ado que dá ao sujeito 1 o estado conclusivo de urbano, expresso, como já afirmamos, no particípio passado de aspectualidade terminativa do processo verbal. O regaço metonímico atualiza a nova ação: a de potencializar o gosto pelo regaço urbanizado e persuadir o sujeito 2. Como há conjunção de interesses entre destinatário e regaço, um se modela ao desejo do outro e, conseqüentemente, a atração é inevitável. O semema da sexualidade confirma-se no texto na presença dos verbos enfiar e querer: "enfia o embainhamento de um atalho,/ para quem quer, quando fora de casa,/ seus dentros e resguardos de quarto". O radical da palavra embainhamento, -bainh, apresenta, no campo semântico, o sentido de vagina, sendo o prefixo $\mathrm{em}$ - designativo de movimento para dentro e o sufixo -mento, ação ou resultado da ação. A palavra embainhamento, composta por derivação parassintética, semantiza a relação ativopassivo, sendo prefixo e sufixo representantes da ação e o radical, nesta situação, de sujeito paciente. Portanto, a axiologia da sexualidade, recorrente nos poemas cabralinos que tematizam Sevilha, aqui está presente em suas duas faces: a uterina e a fálica. Ao atuar reflexivamente para sua urbanização, o sujeito 1 atrai o sujeito 2 para o regaço, espaço semanticamente designativo da concavidade que vai da cintura ao joelho, topos representativo do órgão sexual. Atração similar à sofrida pelos que buscam intimidade no poema "Sevilha", de Quaderna:

O sevilhano usa Sevilha com intimidade,

como se só fosse a casa que ele habitasse.

Com intimidade ele usa ruas e praças;

com intimidade de quarto mais que de casa.

\section{$[\ldots]$}

E mais que intimidade,

Até com amor,

Como um corpo que se usa

E pelo interior.

\section{$[\ldots]$}

nas ruas que o sevilhano

fez para si mesmo,

pequenas e íntimas para

seu aconchego,

sevilhano em quem se encontra

ainda o gosto

de ter a vida à medida

do próprio corpo.

(Melo Neto, 1986:167-8) 
A arquitetura sevilhana equilibra intimidade e exposição e revela, em seu fazer pragmático de "urbanização do regaço", o paradoxo de um planejamento urbano não mecanizado, mas orgânico e perceptivelmente natural, passível de desenvolver a conciliação espacial do privado e do público, para resolver o paradoxo axiológico intimidade $v s$ exposição e conciliar interesses dos sujeitos 1 e 2.

\section{CONSIDERAÇÕES FINAIS}

Zilberberg propõe para afetividade o termo intensidade, e oferece a esta dimensão a regência da extensidade. Segundo o autor: "a intensidade - ou seja, os estados de alma, o sensível - e a extensidade - isto é, os estados de coisas, o inteligível - unem-se uma a outra [e] os estados de coisas estão na dependência dos estados de alma" (Zilberberg, 2006:169). A predominância do sensível sobre o perceptível-inteligível reforça a possibilidade de sensibilização e modalização do destinatário. No poema, a percepção do olhar do espião estende o espaço e intensifica o sentir-se desprotegido, modalizando o sujeito à exploração da espacialidade pluridimensional sevilhana. A geração do gosto pelo regaço urbanizado instaura um espaço tensivo de junção do interior ao exterior, correlação que oferece aos destinatários a continuidade do dentro no fora. $\mathrm{O}$ sujeito 2 revela-se potencialmente ávido de intimidade e, em contrapartida, Sevilha descreve-se como espaço de acolhimento pragmaticamente sexual, tanto de copulação quanto de proteção.

\section{NOTAS}

\footnotetext{
${ }^{1}$ O lexema urbanização apresenta dois significados propostos pelo dicionário Houaiss: "1. conjunto de técnicas e de obras que permitem dotar uma cidade ou área de cidade de condições de infra-estrutura, planejamento, organização administrativa e embelezamento conformes aos princípios do urbanismo. 2. concentração de população em aglomerações de caráter urbano. (2001:2809)". A urbanização proposta no poema refere-se à primeira definição, portanto à reorganização espacial para, num segundo momento, desenvolver o gosto pelo espaço e a concentração populacional proposta na definição 2 .
}

\section{REFERÊNCIAS BIBLIOGRÁFICAS}

BARBOSA, João Alexandre. A imitação pela forma: uma leitura de João Cabral de Melo Neto. São Paulo: Duas Cidades, 1975.

BERTRAND, Denis. Caminhos de semiótica literária. Tradução do Grupo CASA. Bauru: EDUSC, 2003.

CRESPO, Angel. "Introducción: la poesia de Cabral de Melo". In: MELO NETO, João Cabral. Antologia poética. Introdução, seleção e tradução de Angel Crespo. Barcelona: Lumen, 1990, pp.9-32.

FONTANILLE, Jacques \& ZILBERBERG, C. Tensão e significação. Tradução de Ivã Carlos Lopes et al. São Paulo: Discurso Editorial: Humanitas/FFLCH/USP, 2001. \& LOMBARDO, Patrizia, RALLO-DITCHE, Elizabeth. Dictionnaire des Passions Littéraires. França: Belin, 2005. 
GREIMAS, Algirdas Julien. Sobre o sentido: ensaios semióticos. Tradução de Ana Cristina C. Cezar. Petrópolis: Vozes, 1975.

\& COURTÉS, Joseph. Dicionário de semiótica. Tradução de Alceu Dias Lima et al. São Paulo: Cultrix, s.d.

HOUAISS, Antônio e VILLAR, Mauro de Salles. Dicionário Houaiss da língua portuguesa. Rio de Janeiro: Objetiva, 2001.

JAKOBSON, R. "Lingüística e Poética". In: Lingüística e Comunicação. São Paulo: Cultrix, 1975, p.118-162.

A Dominante. In: LIMA, Luiz Costa. Teoria da Literatura em suas Fontes, $2^{\mathrm{a}}$ ed. Rio de Janeiro: Francisco Alves, 1983, v. 1.

MELO NETO, João Cabral de. Poesias completas: 1940-1965, Rio de Janeiro: José Olympio, 1986.

NUNES, Benedito. João Cabral de Melo Neto. Petrópolis: Vozes, 1971, Coleção Poetas Modernos do Brasil. 265-275.

"Educação pela pedra". In: O dorso do tigre. São Paulo: Perspectiva, s.d., pp.

Revista Colóquio Letras. Paisagem tipográfica - homenagem a João Cabral de Melo Neto (1920-1999). Lisboa: Fundação Calouste Gulbenkian, jul-dez 2000, num. $157 / 158,463 \mathrm{p}$.

SECCHIN, Antônio Carlos. João Cabral: a poesia do menos. São Paulo: Duas Cidades; Brasília: INL, Fundação Nacional Pró-Memória, 1985

ZILBERBERG, Claude. "Síntese da gramática tensiva". In: Significação - revista brasileira de semiótica. Tradução de Luiz Tatit e Ivã Carlos Lopes. São Paulo: Annablume, junho de 2006, no 25, p. 163-204.

\section{ANEXO}

1. A urbanização do regaço

1. Os bairros mais antigos de Sevilha

2. criaram uma urbanização do regaço,

3. para quem, em meio a qualquer praça,

4. sente o olho de alguém a espioná-lo,

5. para quem sente nu no meio da sala

6. e se veste com os cantos retirados.

7. Com ruas feitas com pedaços de rua,

8. se agregando mal, por mal colados,

9. com ruas feitas apenas com esquinas

10. e por onde o caminhar fia quadrado,

11. eles têm abrigos e íntimos de corpo

12. nos recantos em desvão e esconsados. i.

13. Com ruas medindo corredores de casas,

14. onde um balcão toca o do outro lado,

15. com ruas arruelando mais, em becos,

16. ou alargando, mas em mínimos largos,

17. os bairros mais antigos de Sevilha

18. criam o gosto pelo regaço urbanizado.

19. Eles têm o aconchego que a um corpo 
20. dá estar noutro, interno ou aninhado,

21. para quem torce a avenida devassada

22. e enfia o embainhamento de um atalho,

23. para quem quer, quando fora de casa,

24. seus dentros e resguardos de quarto.

2.

\section{$O$ regaço urbanizado}

1. Os bairros mais antigos de Sevilha

2. criam o gosto pelo regaço urbanizado.

3. Com ruas feitas apenas com esquinas

4. e por onde o caminhar fia quadrado,

5. para quem sente nu no meio da sala

6. e se veste com os cantos retirados.

7. com ruas medindo corredores de casas,

8. onde um balcão toca o do outro lado,

9. para quem torce a avenida devassada

10. e enfia o embainhamento de um atalho,

11. com ruas feitas com pedaços de rua,

12. se agregando mal, por mal colados,

13. para quem, em meio a qualquer praça,

14. sente o olho de alguém a espioná-lo,

15. os bairros mais antigos de Sevilha

16. criaram uma urbanização do regaço, 2

17. Com ruas arruelando mais, em becos,

18. ou alargando, mas em mínimos largos,

19. eles têm abrigos e íntimos de corpo

20. nos recantos em desvão e esconsados.

21. Eles têm o aconchego que a um corpo

22. dá estar noutro, interno ou aninhado,

23. para quem quer, quando fora de casa,

24. seus dentros e resguardos de quarto.

3.

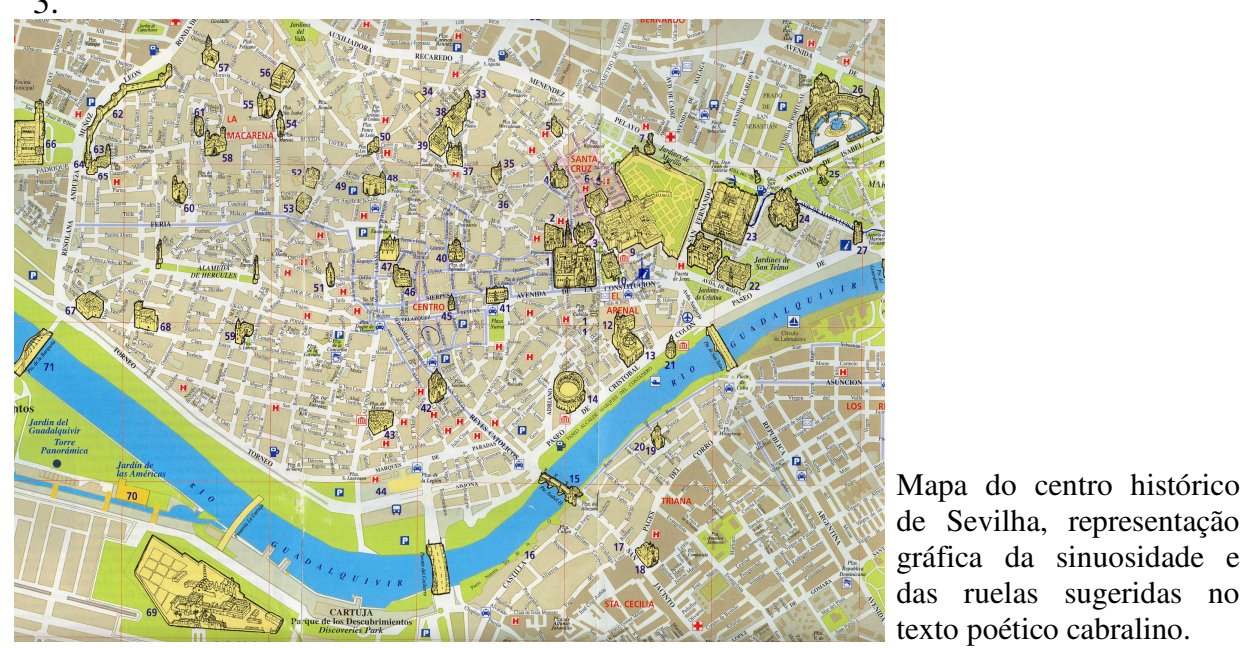




\section{Como citar este artigo:}

BORSATO, Fabiane Renata. A dimensão figurativa em poemas de A educação pela pedra, de João Cabral de Melo Neto. Estudos Semióticos. [online] Disponivel na Internet via WWW.URL: http://www.fflch.usp.br/dl/semiotica/es. Editor Peter Dietrich. Número 4, São Paulo, 2008.

Acesso em "dia/mês/ano". 